\title{
A rapid screening method to evaluate the impact of nanoparticles on macrophages $\dagger$
}

\begin{abstract}
Inès Mottas, ${ }^{a, b}$ Ana Milosevic, ${ }^{c}$ Alke Petri-Fink, ${ }^{c, d}$ Barbara Rothen-Rutishauser ${ }^{c}$ and Carole Bourquin*a,b

Nanotechnology is an emerging and highly promising field to develop new approaches for biomedical applications. There is however at present an unmet need for a rapid and universal method to screen nanoparticles (NP) for immunocompatibility at early stages of their development. Indeed, although many types of highly diverse NP are currently under investigation, their interaction with immune cells remains fairly unpredictable. Macrophages which are professional phagocytic cells are believed to be among the first cell types that take up NP, mediating inflammation and thus immunological responses. The present work describes a highly reproducible screening method to study the NP interaction with macrophages. Three essential questions are answered in parallel, in a single multiwell plate: Are the NP taken up by macrophages? Do the NP cause macrophage cell death? Do the NP induce inflammatory reactions? This assay is proposed as a standardized screening protocol to obtain a rapid overview of the impact of different types of NP on macrophages. Due to high reproducibility, this method also allows quality control assessment for such aspects as immune-activating contaminants and batch-to-batch variability.
\end{abstract}

\section{Introduction}

Nanomedicine represents a rapidly developing field which bears high promise for many clinical applications. ${ }^{1}$ Nanoparticles (NP) are defined as particulate objects from 1 to $100 \mathrm{~nm}$ in diameter with specific properties that cannot be found in bulk materials. ${ }^{2}$ NP can be designed to possess unique optical properties allowing novel imaging and diagnostic applications, ${ }^{3}$ or to serve as highly modular drug delivery systems that target specific organs or cell populations within the body, thus improving drug efficacy and at the same time reducing unwanted side effects. ${ }^{4-7}$ It is even becoming possible to combine diagnostic and therapeutic characteristics in engineered NP to yield promising theranostic tools. ${ }^{8}$ Because NP themselves can have an impact on cell viability and function, it is critical to assess their biocompatibility early in the

${ }^{a}$ Chair of Pharmacology, Department of Medicine, Faculty of Science, University of Fribourg, Chemin du Musée 5, 1700 Fribourg, Switzerland

${ }^{b}$ School of Pharmaceutical Sciences, University of Geneva, University of Lausanne, and Department of Anesthesiology, Pharmacology, and Intensive Care,

Rue Michel-Servet 1, 1211 Geneva, Switzerland.E-mail: carole.bourquin@unige.ch; Tel: +41223790701

${ }^{c}$ Adolphe-Merkle Institute, University of Fribourg, Chemin des Verdiers 4, 1700 Fribourg, Switzerland

${ }^{d}$ Chemistry Department, University of Fribourg, Chemin Du Musée 9, 1700 Fribourg, Switzerland

$\dagger$ Electronic supplementary information (ESI) available. development process. Indeed, even if NP are individually well characterized with respect to many factors such as shape, size, zeta potential, and colloidal stability, the outcome of their interaction with cells (which also differ in type and function) is difficult to predict. ${ }^{9}$ To rapidly and efficiently select appropriate NP for clinical applications, it is essential to develop efficient screening methods to test their interactions with the cell types that they will encounter in the organism.

Macrophages can be found in all tissues of the body, and they are particularly abundant at sites that are in direct contact with the environment such as lungs, skin, and gastrointestinal mucosa, or in organs with important blood supply such as the spleen, kidney and liver. ${ }^{10}$ The prime ability of macrophages is the engulfment of microorganisms, damaged cells and other particulate materials by phagocytosis. ${ }^{11,12}$ For these reasons, macrophages are a critical cell type with respect to biomedical NP applications, as they are considered to be one of the first cell populations that are encountered by NP entering the body. ${ }^{12}$ Through their phagocyte function, these cells mediate clearance of NP from the body and thus modulate NP bioavailability. ${ }^{13}$ In addition to their scavenger role, macrophages are among the first cells to initiate an inflammatory immune response. When they recognize specific microbial components as a danger signal, macrophages rapidly produce proinflammatory cytokines such as interleukin 6 (IL-6) and tumor necrosis factor- $\alpha(\mathrm{TNF}-\alpha)$ in order to initiate a down-stream immune response. ${ }^{10}$ If NP themselves are recognized as a danger signal, or if traces of immune-activating substances are 
present in the NP preparation, macrophages may trigger an immune response against the material. ${ }^{14}$ In addition, some NP have been reported to affect viability of macrophages. ${ }^{15}$ This immunotoxicity may negatively affect the maintenance of immunity against pathogens.

It is thus essential to characterize the modes of interaction of macrophages with NP designed for biomedical purposes at the early stages of their development. Indeed, such assays should be performed for every NP batch before further biological testing, as there can be considerable variation between individual NP preparations. Several studies have reported investigation of NP-macrophage interactions, ${ }^{12,16-18}$ but the experiments were generally performed in a serial manner, requiring a high concentration of particles to assess all essential parameters in order to test the NP. One report described a screening method to assess liposome interactions with macrophages using fluorescence microscopy to quantify uptake and cell viability. ${ }^{19}$ However microscopy represents a challenge to acquire and analyze all samples equally, and the assessment of more than 3 parameters at the same time is unusual. ${ }^{20}$ Another group described how to screen NP cytotoxicity on fibroblasts and alveolar epithelial cells. ${ }^{21}$ This method could however not easily be applied to macrophages, as NP internalization and immune activation were not considered. Taken together, there is an unmet need for a standardized method to assess the essential parameters of NP-macrophage interactions rapidly and efficiently.

Here we present an automated screening assay by which NP cytotoxicity, cellular uptake, and immune activating effects on macrophages in vitro are characterized in a standardized manner. These three essential aspects of NP-macrophage interactions can be assessed in a single culture plate within a $24 \mathrm{~h}$ experiment. Since NP themselves may interfere with different readouts, ${ }^{22,23}$ we proposed adequate controls in order to ensure that NP interferences do not lead to an over- or underestimation of the NP effects. Cost effectivity and high reproducibility of the protocol make the screening method attractive for identifying a lead candidate for biomedical purposes, for quality control of each NP preparation and for the detection of immune-activating contaminants.

\section{Materials and methods}

\section{NP synthesis}

Citrate-stabilized gold NP were synthesized as previously reported. ${ }^{24}$ To enhance NP colloidal stability, ${ }^{25}$ the gold core was coated with a polymer mixture comprising of polyvinyl alcohol (PVA; Mowiol 3-85, $M_{\mathrm{w}}=15000 \mathrm{Da}$ ) (Calbiochem, EMD bioscience, Inc. La Jolla, USA) and a vinylalcohol-vinylamine copolymer $\left(\mathrm{NH}_{2}\right.$ PVA; M12, $M_{\mathrm{w}}=240000 \mathrm{Da}$ ) (Erkol S.A., Tarragona, Spain) as previously described for hetero-functionalized AuNP. ${ }^{24}$ For this study, polymers were fluorescently labeled with a Cyanine5 NHS dye (Cy5; Lumiprobe, Hannover, Germany) via ester bond formation for the polyvinyl alcohol polymer and the amide bond for the vinylalcohol-vinylamine copolymer. For fluorescently-labeled AuNP the polymer mixture was composed of $0.5 \mathrm{mg} \mathrm{ml}^{-1}$ of $\mathrm{NH}_{2} \mathrm{PVA}, 0.375 \mathrm{mg} \mathrm{ml}^{-1}$ of $\mathrm{NH}_{2}$ PVA-noCy5, $1.612 \mathrm{mg} \mathrm{ml}^{-1}$ PVA and $4.7 \mathrm{mg} \mathrm{ml}^{-1}$ PVAnoCy5. For unlabeled AuNP the polymer mixture was composed of $0.875 \mathrm{mg} \mathrm{ml}^{-1} \mathrm{NH}_{2}$ PVA-noCy 5 and $6.3 \mathrm{mg} \mathrm{ml}^{-1}$ PVAnoCy5. The following NP were analyzed: citrate-stabilized gold NP (citrate AuNP) and polymer-coated NP with Cy5 labeling ( $\mathrm{NH}_{2}$ PVA-AuNP). Polymer-coated NP without Cy5 labeling $\left(\mathrm{NH}_{2}\right.$ PVA-AuNP-noCy5) were used only as control in the uptake experiment (Fig. 2). Additional AuNP formulations were used in order to validate the method (see the ESI $\dagger$ ).

\section{NP characterization and stability}

All NP were characterized in terms of their optical properties, size and zeta potential. Optical properties were characterized using a UV-Vis spectrometer (Jasco Europe S.R.L., Milano, Italy), where the spectra of NP were measured in water for citrate AuNP and PBS for $\mathrm{NH}_{2}$ PVA-AuNP and $\mathrm{NH}_{2}$ PVA-AuNPnoCy5. The size distribution of the Au core was determined by transmission electron microscopy (TEM) using a FEI Tecnai Spirit (FTI) transmission electron microscope. The hydrodynamic radius was determined by dynamic light scattering (DLS) (LS Instruments A.G., Fribourg, Switzerland) in depolarized DLS (DDLS) mode. DDLS measurements were performed at an angle of $90^{\circ}$ in water for citrate AuNP and in PBS for $\mathrm{NH}_{2}$ PVA-AuNP and $\mathrm{NH}_{2}$ PVA-AuNP-noCy5. The zeta potential was measured using a ZetaSizer (Brookhaven Instruments Corporation, Holtsville, USA) in water for AuNP and PBS for $\mathrm{NH}_{2}$ PVA-AuNP and $\mathrm{NH}_{2}$ PVA-AuNP-noCy5.

NP colloidal stability was assessed using UV-Vis and DDLS for time resolved measurements over $24 \mathrm{~h}$ at $37^{\circ} \mathrm{C}$. The stability of all three NP was tested in PBS and complete cell culture medium (cDMEM) consisting of high glucose $\left(4.5 \mathrm{~g} \mathrm{l}^{-1}\right)$ Dulbecco's modified Eagle's medium (DMEM) (Biowest, Nuaillé, France) was supplemented with 1\% glutamine (PAA laboratories, Pashing, Austria), $1 \mathrm{nM}$ sodium pyruvate, $10 \%$ fetal bovine serum (FBS) (Biological Industries, Beit Ha'Emeq, Israel) and 0.5\% ciproxine (Bayer, Zürich, Switzerland).

\section{Macrophage cell line and NP exposure}

J774.1 macrophages (ATCC, Manassas, USA) were cultivated in cDMEM at $37{ }^{\circ} \mathrm{C}$ and $5 \% \mathrm{CO}_{2}$. Before each experiment, cells were concentrated to $5 \times 10^{5}$ cells per $\mathrm{mL}$ before adding $100 \mu \mathrm{l}$ per well $\left(5 \times 10^{4}\right.$ cells per well $)$ in flat-bottom 96-well plates (Corning, New York, USA). After overnight incubation, medium was replaced by $50 \mu \mathrm{l}$ fresh cDMEM. NP, polymers and other test substances were added as indicated at $2 \times$ concentration in $50 \mu \mathrm{l}$ cDMEM. For all NP, the final working concentration was $10 \mu \mathrm{g} \mathrm{ml}^{-1}$ gold (determined by UV-Vis at $400 \mathrm{~nm}$ ), corresponding to approximately $1.8 \times 10^{10} 17 \mathrm{~nm}$ gold particles per $\mathrm{mL}$. For polymer controls $\left(\mathrm{NH}_{2} \mathrm{PVA}\right.$ and $\mathrm{NH}_{2}$ PVA-noCy5), the working concentration corresponds to the concentration of the polymer on the NP. As a positive control for immune activation, J774.1 macrophages were cultured with $100 \mathrm{ng} \mathrm{m} \mathrm{m}^{-1}$ lipopolysaccharide (LPS; Invivogen, Toulouse, France). Staurosporine was used to induce apoptotic cell death 
(1 nM; Sigma-Aldrich, Saint-Louis, USA). To control NP interferences, the positive controls were tested in combination with NP added after $23 \mathrm{~h}$. After a $24 \mathrm{~h}$ incubation, supernatants were stored at $-20{ }^{\circ} \mathrm{C}$ for cytokine quantification and $100 \mu \mathrm{l}$ per well PBS were added to the cells for light microscopy and flow cytometry analysis. Please refer to the ESI $\uparrow$ for a list of required materials and instruments and to Fig. S1 $\uparrow$ for further details on the 96-well plate organization.

\section{Flow cytometry}

For flow cytometry, J774.1 cells in PBS were gently detached by pipetting and transferring to U-bottom 96-well plates for staining as described below. All parameters were assessed in one 96-well plate in a single measurement (Fig. S1†). Analysis was performed with a MACSquant analyzer 10 using the chill 96-rack (both from Miltenyi Biotec, Bergisch Gladbach, Germany). Every well was gently mixed automatically before acquisition of $50 \mu \mathrm{l}$. Data in the FCS 3.1 format were analyzed using the FlowJo software version 10.0.8r1 (FlowJo Analysis software, Ashland, USA).

To measure viability, the cells were incubated with Pacific Blue-labeled annexin V diluted, $1: 100$, in annexin V binding buffer (both from Biolegend, San Diego, USA). After $30 \mathrm{~min}$ incubation at room temperature protected from light, one volume of annexin V binding buffer was added. Propidium iodide (PI; Sigma-Aldrich, Saint-Louis, USA) diluted, $1: 200$, in PBS was automatically added by using the MACSquant analyzer 10 just before mixing and acquisition. For quantification of NP uptake, the proportion of Cy5-positive cells within live cells (annexin V/PI double-negative population) was determined.

To assess macrophage activation, the J774.1 cells were stained with a Zombie Green fixable viability dye (Biolegend, San Diego, USA) according to the manufacturer's protocol. After washing with flow cytometry buffer consisting of PBS supplemented with 2 mM EDTA (Calbiochem, Darmstadt, Germany) and 0.5\% BSA (PAA laboratories, Pashing, Austria), the cells were incubated with unlabeled anti-CD16/32 to block Fc receptors (Biolegend, San Diego, USA). After $10 \mathrm{~min}$ at $4{ }^{\circ} \mathrm{C}$, specific antibodies for surface activation markers or their respective isotype controls in flow cytometry buffer were added: Pacific Blue-CD80, PE-CD86, PE/Cy7-CD11b and APC/Cy7-MHCII (all from Biolegend, San Diego, USA). After further $30 \mathrm{~min}$ at $4{ }^{\circ} \mathrm{C}$, the cells were washed once with flow cytometry buffer before acquisition.

\section{Bright field imaging}

The live cell morphology and density were pictured by bright field microscopy (CKX53, Olympus, Tokyo, Japan) at 10× magnification.

\section{ELISA}

To quantify cytokine secretion, ELISA Max Deluxe sets for mouse interleukin 6 (IL-6) and tumor necrosis factor- $\alpha$ (TNF- $\alpha$ ) (both from Biolegend, San Diego, USA) were used according to the manufacturer's protocol in half-well plates. Absorbance was measured at $450 \mathrm{~nm}$ with an Infinite $200 \mathrm{PRO}$ plate-reader
(TECAN, Männedorf, Switzerland) where the reference absorbance at $570 \mathrm{~nm}$ was subtracted. Cytokine concentrations were calculated according to the standard curve performed in duplicate.

\section{Statistical analysis}

Graphs were plotted with the GraphPad Prism software version 6.0e (GraphPad Software, San Diego, USA). The statistical significance of multiple groups in comparison to the control group (untreated sample) was assessed using one-way ANOVA followed by Dunnett's multiple comparison test. An unpaired $t$-test was used in Fig. 4 to compare two groups. For all experiments with the J774.1 cells, graphs show the mean and error bars indicate the standard error of the mean (SEM) of four or five independent experiments performed on different days.

\section{Results}

This rapid method presented herein to test NP-macrophage interactions and cellular responses is based on a multi-parameter analysis using a macrophage cell line. After exposure of macrophages to NP in a 96-well cell culture plate, the cells were analyzed by flow cytometry and bright field microscopy, whereas supernatants were collected for ELISA quantification of cytokines. This strategy allows to determine several crucial aspects of interactions between NP and macrophages in parallel from a single culture plate (Scheme 1): NP-related cytotoxicity (1), cellular uptake of NP (2), and proinflammatory activation (3).

\section{NP characterization and stability}

To illustrate the multi-parameter screening method for NPmacrophage interactions, we chose to use polymer-coated gold particles (AuNP) as model NP. AuNP possess several advantages which make them promising candidates for biomedical applications, including tunable sizes, the possibility of surface functionalization, optical properties that enable their detection, and low toxicity. ${ }^{26}$ We selected hetero-functionalized $\mathrm{NH}_{2}$ PVA-AuNP as a model for the assay, as we have previously shown that these NP are best taken up among the formulations tested. ${ }^{24}$ Citrate-stabilized AuNP were coated with the vinylalcohol-vinylamine copolymer/polyvinyl alcohol polymer mixture through ligand exchange as described. ${ }^{24}$ In order to assess NP uptake by macrophages, the first polymer layer was labeled with the Cy5 fluorescent dye $\left(\mathrm{NH}_{2} \mathrm{PVA}-\mathrm{AuNP}\right)$. NP with unlabeled polymers were used as a control $\left(\mathrm{NH}_{2} \mathrm{PVA}\right.$-AuNPnoCy5). Cy5 (650/670), a far red dye, was selected to limit potential fluorescence interferences with the gold core (Fig. 1B). All AuNP were thoroughly characterized by conventional methods: TEM (gold core size distribution), UV-Vis (particle size and concentration), DDLS (hydrodynamic size), and zeta potential (Fig. 1). DDLS was preferred to characterize the particle size (hydrodynamic radius), as it was previously shown to have an advantage over conventional dynamic light scattering (DLS) for measurements in a complex fluid such as cell 


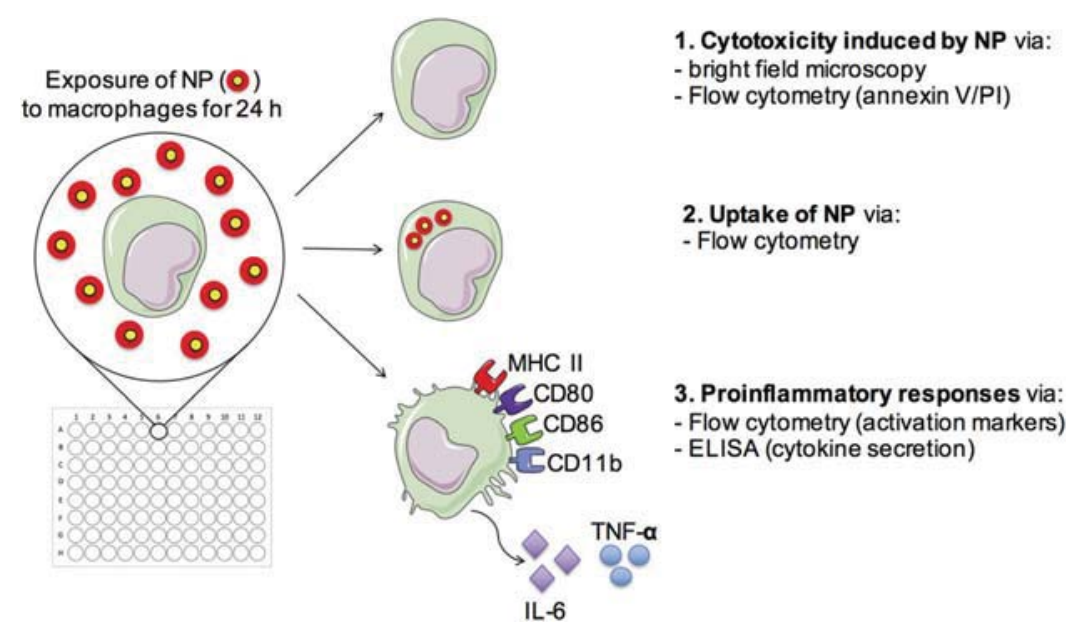

Scheme 1 Parameters measured by NP screening assay. J774.1 macrophages are exposed to NP for $24 \mathrm{~h}$. Three effects of NP-macrophage interactions are measured in parallel. (1) Cytotoxicity is assessed by bright field microscopy and measured by flow cytometry with annexin $\mathrm{V}$ and propidium iodide (PI) staining. (2) Uptake of fluorescently-labeled NP by macrophages is determined by flow cytometry. (3) The immune activation phenotype is determined by flow cytometry measurement of cell surface activation markers (MHC II, CD80, CD86, CD11b) and by quantification of proinflammatory cytokines in the supernatant (IL-6, TNF- $\alpha$ ).

A

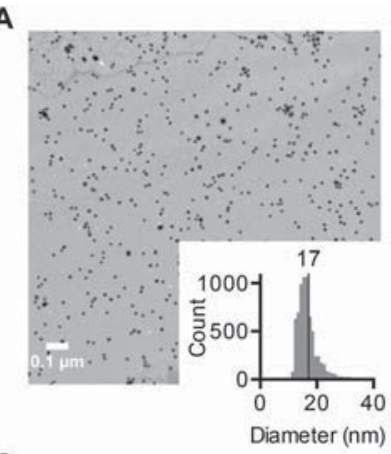

C

\begin{tabular}{|c|c|c|c|}
\hline \multirow{2}{*}{ NP type } & \multicolumn{2}{|c|}{ Diameter $(\mathrm{nm})$} & \multirow{2}{*}{ zeta-potential (mV) } \\
\hline & TEM & DDLS & \\
\hline AuNP & $16.5 \pm 3.7$ & $28^{\mathrm{a}} \pm 0.8$ & $-44.25^{a} \pm 1.2$ \\
\hline $\mathrm{NH}_{2}$ PVA-AuNP-noCy5 & n.a. & $47^{b} \pm 0.2$ & $7.54^{b} \pm 5.93$ \\
\hline $\mathrm{NH}_{2}$ PVA-AuNP & n.a. & $70^{b} \pm 3$ & $6.06^{\mathrm{b}} \pm 2.11$ \\
\hline
\end{tabular}

Fig. 1 Characterization of AuNP. (A) TEM image of AuNP with the corresponding diameter distribution histogram. (B) UV-Vis spectra of NP. Measurements were performed in the media used for synthesis: water (citrate AuNP) or PBS $\left(\mathrm{NH}_{2} \mathrm{PVA}-\mathrm{AuNP}-\mathrm{noCy} 5\right.$ and NH$\left.{ }_{2} \mathrm{PVA}-\mathrm{AuNP}\right)$. Data are normalized according to absorbance at $400 \mathrm{~nm}$. a.u.: area unit. (C) Table shows NP core diameter obtained via TEM, NP hydrodynamic diameter obtained via depolarized dynamic light scattering (DDLS) measurements and zeta potential measurements ( ${ }^{a}$ measurements performed in water; ${ }^{\mathrm{b}}$ measurements performed in PBS, both without incubation) at $40 \mu \mathrm{g}$ AuNP per ml. Mean \pm SD of 3-5 measurements for DDLS and 10 measurements for zeta-potential are shown.

culture medium. ${ }^{27} \mathrm{NP}$ stability in complete macrophage culture medium (cDMEM) was determined after $24 \mathrm{~h}$ incubation at $37{ }^{\circ} \mathrm{C}$ by start/end point UV-Vis measurements and time resolved DDLS (Fig. 2). Although citrate AuNP do not preserve colloidal stability in PBS (data not shown), ${ }^{27}$ these particles were stable in cDMEM, probably due to protein corona formation. ${ }^{28,29}$ Both $\mathrm{NH}_{2}$ PVA-AuNP-noCy5 and $\mathrm{NH}_{2} \mathrm{PVA}-\mathrm{AuNP}$ were stable in cDMEM over $24 \mathrm{~h}$.

\section{Impact of NP on macrophage viability}

As a cellular model, we used the well-described J774.1 murine macrophage cell line, which possesses many of the defining 
A

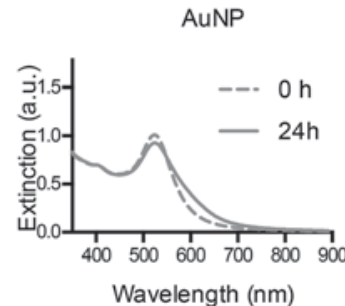

B

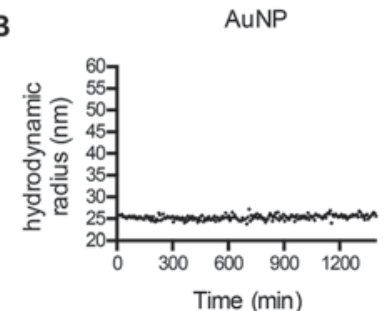

$\mathrm{NH}_{2}$ PVA-AuNP-noCy5

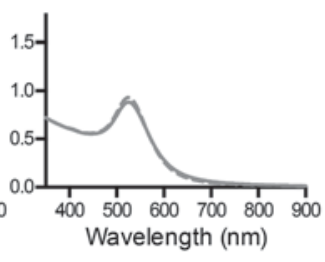

$\mathrm{NH}_{2}$ PVA-AuNP-noCy5

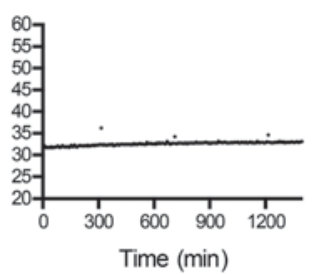

$\mathrm{NH}_{2}$ PVA-AuNP

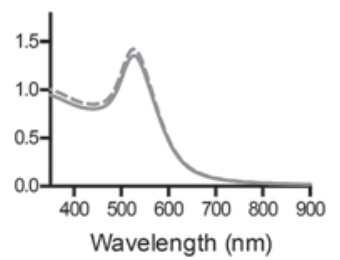

$\mathrm{NH}_{2}$ PVA-AuNP

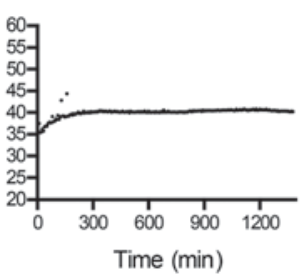

Fig. 2 NP stability in cell culture medium. NP were incubated for $24 \mathrm{~h}$ in complete cell culture medium (cDMEM) at $37^{\circ} \mathrm{C}$. (A) UV-Vis assessment of NP stability. UV-Vis spectra were measured at the beginning of incubation (0 h) and after $24 \mathrm{~h}$. (B) Timeline of DDLS measurements. During incubation DDLS measurements at $90^{\circ}$ angle were performed in a time resolved fashion (every 300 seconds).

characteristics of macrophages. To examine macrophage viability, morphology and confluency, the J774.1 cells were visually assessed by bright field microscopy after a $24 \mathrm{~h}$ culture (Fig. 3A). Staurosporine, which induces apoptotic cell death, strongly reduced the proportion of round live cells. Lipopolysaccharide (LPS), which is a bacterially derived endotoxin used as a positive proinflammatory control, promoted adhesion and spreading of cells, inducing the typical morphology of immune-activated macrophages (arrows). ${ }^{30}$ In contrast, exposure to citrate AuNP, the $\mathrm{NH}_{2} \mathrm{PVA}$ polymer or $\mathrm{NH}_{2}$ PVA-AuNP did not induce any change in morphology, with cells remaining small and round. Some material aggregates (arrows) were seen with $\mathrm{NH}_{2}$ PVA polymer exposure.

Two major mechanisms of cell death can be distinguished, apoptosis and necrosis. Whereas apoptotic cell death does not generally promote inflammation, necrotic cell death leads to the disruption of the cell membrane and release of proinflammatory substances. To investigate whether AuNP induced cell death is by one of these mechanisms, macrophages were assessed by flow cytometry after staining with annexin $\mathrm{V}$ and propidium iodide (PI). Annexin V detects the presence of phosphatidylserine on the outer layer of the membrane bilayer, an early sign of apoptosis, whereas PI intercalates into DNA when the cell membrane is disrupted. ${ }^{31}$ This staining allows easy discrimination between live, apoptotic and dead cells (Fig. 3B, top left). The untreated J774.1 cells show approximately $60 \%$ live cells under these conditions, as this is a cell line with a high proliferation rate and turnover. Our results showed that citrate AuNP, the $\mathrm{NH}_{2}$ PVA polymer and $\mathrm{NH}_{2}$ PVA-AuNP did not decrease the proportion of live cells after a $24 \mathrm{~h}$ exposure, in contrast to staurosporine (Fig. $3 \mathrm{~B}$ and $\mathrm{C}$ ). The $\mathrm{NH}_{2} \mathrm{PVA}$ polymer and $\mathrm{NH}_{2} \mathrm{PVA}-\mathrm{AuNP}$ did increase the proportion of AnnexinV-/PI+ dead cells, although not significantly, suggesting that the polymer may promote necrotic cell death at higher concentrations (Fig. S2 $\dagger$ ). Since the NP themselves could in principle interfere with the measurements (the gold core could for instance affect the PI fluorescence signal with a maximal emission at $538 \mathrm{~nm}$ ), it was necessary to verify that the materials did not affect the fluorescence signals of annexin $\mathrm{V}$ or PI. To verify this point, macrophages were incubated for $24 \mathrm{~h}$ with staurosporine. For the last hour before assessment by flow cytometry, AuNP, the $\mathrm{NH}_{2} \mathrm{PVA}$ polymer or $\mathrm{NH}_{2}$ PVA-AuNP were added to the staurosporine-treated cells. Our results showed that none of these conditions interfere with the annexin V/PI staining, as there was no difference in macrophage viability compared to the cells incubated only with staurosporine (Fig. 3C, right panel). We chose to use flow cytometry rather than a metabolic assay such as the 3-(4,5-dimethylthiazol-2-yl)-2,5 diphenyltetrazolium (MTT) test to assess cell viability, because this technique allows a multiparametric readout. In addition, some NP have been described to absorb the MTT reagent ${ }^{32}$ or to interfere directly with colorimetric reading, ${ }^{33}$ and the MTT assay does not directly measure cell counts but rather depends on mitochondrial enzymatic activity. In the case where NP could affect mitochondrial activity, the MTT reading would also be affected. ${ }^{34}$ Thus, we confirmed by using two independent methods that $\mathrm{NH}_{2}$ PVA-AuNP do not affect macrophage viability.

\section{Uptake of fluorescently labeled NP by macrophages}

Macrophages are specialized in the uptake of particulate materials such as tissue debris and certain pathogens. ${ }^{12}$ Since uptake by macrophages critically modifies the pharmacokinetics and biodistribution of the NP in the body, ${ }^{35}$ it is essential to assess NP uptake by macrophages early in the development process of any particles designed for biomedical applications. 
A

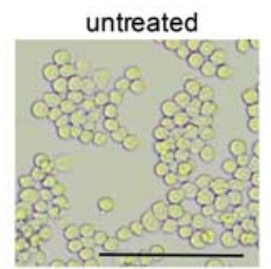

AuNP

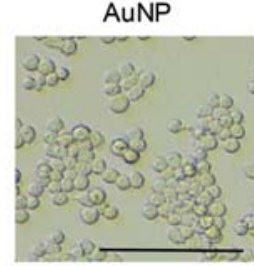

B
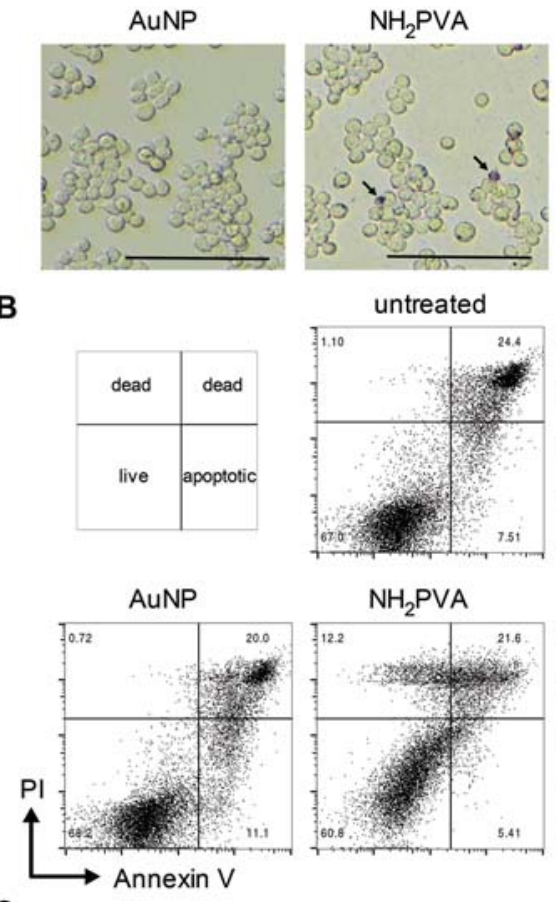

4.15
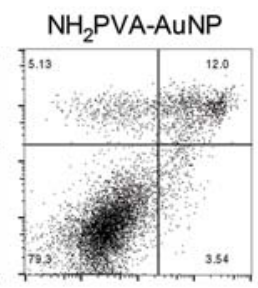

C
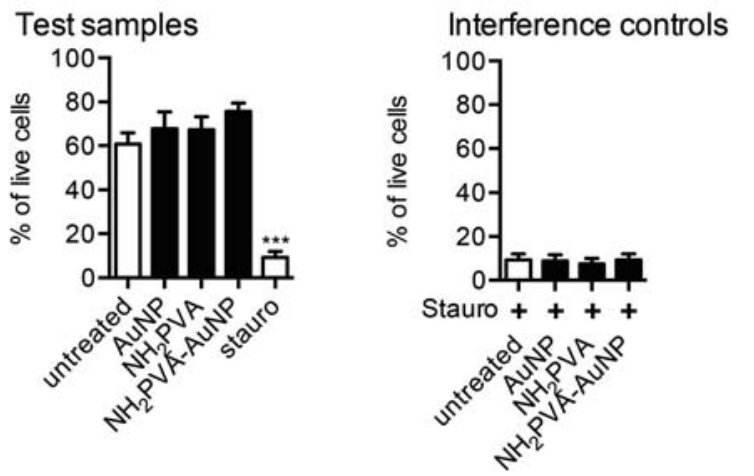

Fig. 3 Impact of NP on macrophage viability. J774.1 macrophages were incubated for $24 \mathrm{~h}$ with $\mathrm{NP}$, the $\mathrm{NH}_{2} \mathrm{PVA}$ polymer or staurosporine. (A) Representative bright field images at 10x magnification. Scale bar: $100 \mu \mathrm{m}$. (B and C) Flow cytometry analysis with annexin V and PI. (B) One representative dot plot per condition is shown. (C) Percentage of live (annexin V/PI double-negative) cells. Interference controls (right panel): macrophages were incubated with staurosporine for $24 \mathrm{~h}$. After $23 \mathrm{~h}$, the NP or $\mathrm{NH}_{2} \mathrm{PVA}$ polymer were added for the last hour before analysis. Each bar represents mean \pm SEM of 5 independent experiments. Asterisks (***, $P<0.001$ ) indicate significant differences with the untreated group using one-way ANOVA followed by Dunnett's multiple comparison test.

Flow cytometry analysis detects morphological changes proportionally to the size and granularity of the cell by forward scatter (FSC) and side scatter (SSC), respectively. In conse- quence, if NP are taken up, the SSC intensity may increase. ${ }^{36-38}$ However our data show no significant SSC shift when comparing NP-treated cells with untreated cells (Fig. 4A). As the cell size and granularity change when cells are dying, ${ }^{39}$ this technique requires the exclusion of dying cells before the uptake analysis. Therefore, we first gated on live (annexin V/PI double-negative) cells.

A more sensitive strategy to determine whether $\mathrm{NH}_{2}$ PVA-AuNP are taken up by macrophages is to use the fluorescently labeled NP. The J774.1 cells were exposed for $24 \mathrm{~h}$ at $37{ }^{\circ} \mathrm{C}$ to $\mathrm{NH}_{2}$ PVA-AuNP labeled with $\mathrm{Cy} 5$ and fluorescence intensity was then quantified by flow cytometry. Macrophages incubated with Cy5-labeled $\mathrm{NH}_{2} \mathrm{PVA}-\mathrm{AuNP}$ or with the Cy5labeled $\mathrm{NH}_{2} \mathrm{PVA}$ polymer alone showed higher fluorescence than non-exposed macrophages (Fig. 4B, left panel). Indeed, at least $80 \%$ of the macrophages exposed to $\mathrm{NH}_{2} \mathrm{PVA}$-AuNP were Cy5-positive (Fig. 4C, left panel). To determine whether the NP were actively taken up by the cells, incubation was also performed at $4{ }^{\circ} \mathrm{C}$, a temperature at which many active processes are inhibited. At $4{ }^{\circ} \mathrm{C}$, the percentage of Cy5-positive cells dropped significantly to approximately $40 \%$ for cells exposed to $\mathrm{NH}_{2}$ PVA-AuNP (Fig. 4C), suggesting that the NP are taken up at least in part by an active process. The Cy5-positive macrophages exposed to NP at $4{ }^{\circ} \mathrm{C}$ may be decorated with NP on their surface, as this would not require an active uptake.

To verify that the $\mathrm{NH}_{2}$ PVA polymer and the NP themselves do not affect the detection of the Cy5 fluorescent signal, we incubated macrophages with the $\mathrm{NH}_{2} \mathrm{PVA}$ polymer or $\mathrm{NH}_{2}$ PVA-AuNP without Cy5 at $37{ }^{\circ} \mathrm{C}$ and $4{ }^{\circ} \mathrm{C}$ (Fig. 4A and B, right panels). No increase in fluorescence was seen, indicating that the $\mathrm{NH}_{2} \mathrm{PVA}$ polymer and $\mathrm{NH}_{2} \mathrm{PVA}$-AuNP do not affect Cy5 detection by flow cytometry.

\section{Production of proinflammatory cytokines by macrophages after NP exposure}

In addition to cytotoxicity and cellular uptake, it is essential to assess NP-induced immune activation on macrophages. Indeed, compounds used during NP synthesis often contain trace contaminations of immune-activating substances that can lead to important inflammatory reactions. LPS, an endotoxin present on Gram-negative bacteria, is a frequent contaminant that can induce strong proinflammatory responses even at picogram concentrations in humans. ${ }^{40}$

As J774.1 macrophages show high sensitivity to LPS and other pathogen contaminants, ${ }^{41}$ we propose to use these cells as a highly reactive and cost-limiting strategy to detect immune-activating contaminations. The activation of macrophages leads to the secretion of several proinflammatory cytokines such as interleukin 6 (IL-6) and tumor necrosis factor- $\alpha$ $(\mathrm{TNF}-\alpha)$, which represent the first step towards a generalized inflammatory response. We quantified cytokine concentration by ELISA in the culture supernatant from the same wells of NP-exposed macrophages used for flow cytometry. After $24 \mathrm{~h}$ of exposure to citrate AuNP, the $\mathrm{NH}_{2} \mathrm{PVA}$ polymer or $\mathrm{NH}_{2}$ PVA-AuNP, none of these conditions induced either IL- 6 or TNF- $\alpha$ (Fig. 5, left panels). LPS was used as a positive control 
A

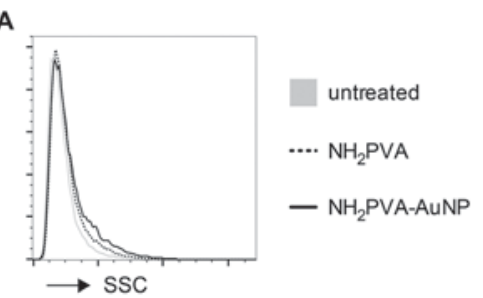

B
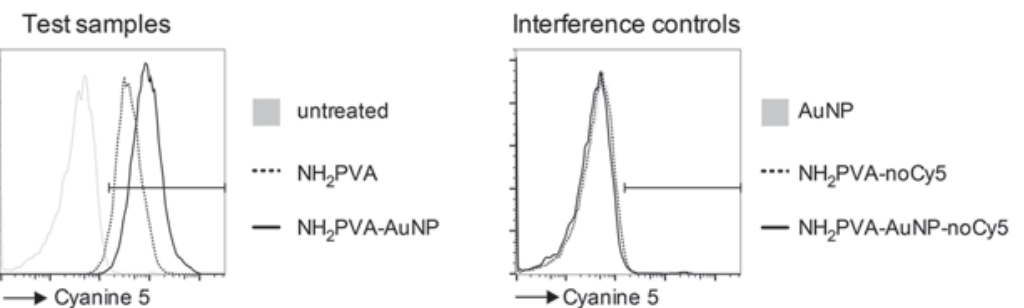

C

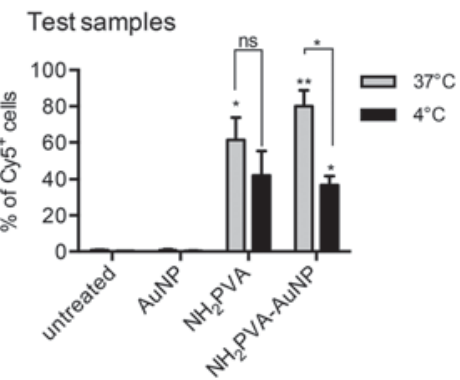

Interference controls

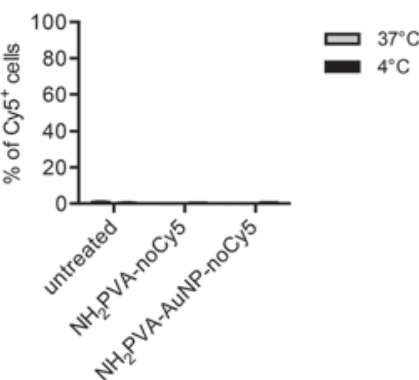

Fig. 4 Uptake of NP by macrophages. J774.1 macrophages were incubated for $24 \mathrm{~h}$ at $37^{\circ} \mathrm{C}(\mathrm{A}-\mathrm{C})$ or $4{ }^{\circ} \mathrm{C}\left(\mathrm{C}\right.$, as indicated) with the NP or $\mathrm{NH} \mathrm{P}_{2} \mathrm{PVA}$ polymer. Uptake was analyzed by flow cytometry after gating on live (annexin V/PI double-negative) cells. (A) Representative modal histograms of the SSC signal. (B and C) Representative modal histograms of Cy5 (B) and percentage of $\mathrm{Cy}^{+}$cells (C) for macrophages incubated with Cy5-labeled $\mathrm{NP}$ and the polymer (test samples, left panel) or with unlabeled NP and the polymer (interference controls, right panel). Each bar represents mean \pm SEM of 4 independent experiments (unlabeled NP and the polymer: 2 independent experiments). Asterisks $(*, P<0.05 ; * *, P<0.01)$ without brackets indicate comparison to the untreated group using one-way ANOVA followed by Dunnett's multiple comparison test. Asterisk $(*, P<0.05)$ with brackets indicates comparison using unpaired $t$-test. ns: not significant.

and for all cytokines a significant increase compared to the untreated control was observed.

To verify that the NP themselves did not interfere with the ELISA assay, the J774.1 cells were exposed to LPS for $24 \mathrm{~h}$ to induce proinflammatory cytokines and citrate AuNP, the $\mathrm{NH}_{2}$ PVA polymer or $\mathrm{NH}_{2}$ PVA-AuNP were added only for the last hour of incubation, a time frame which was sufficient for NP uptake (Fig. S3†). Although the cytokine concentration was expected to be the same under all conditions, a lower absorbance was measured by ELISA under the conditions with NP or the polymer (Fig. 5, right panels), suggesting that both materials interfere with the assay at the concentrations used. The lower signal intensity could be due to cytokine adsorption to the material surface.

\section{Immune activation phenotype of macrophages after NP exposure}

To verify the NP-induced activation of macrophages by a second readout, we examined whether $\mathrm{NH}_{2}$ PVA-AuNP caused a switch from a naïve to an activated phenotype of the J774.1 cells. Upon immune activation, the cell surface markers of macrophages change to enhance their interactions with other immune cells. We therefore analyzed the up-regulation of key surface activation markers such as major histocompatibility complex class II (MHC II) molecules, that mediate antigen presentation to T cells; CD80 and CD86, two co-stimulatory molecules that support efficient T-cell activation; CD11b a leukocyte integrin associated with migration and adhesion that is essential in inflammation. ${ }^{42}$ Citrate AuNP, the $\mathrm{NH}_{2} \mathrm{PVA}$ polymer and $\mathrm{NH}_{2}$ PVA-AuNP did not induce up-regulation of any of the tested activation markers on the J774.1 cells, in contrast to the immune activator LPS (Fig. 6, left panels). To control NP interference, we incubated the macrophages with LPS for $24 \mathrm{~h}$ to induce the up-regulation of these typical activation markers. Citrate AuNP, the $\mathrm{NH}_{2} \mathrm{PVA}$ polymer or $\mathrm{NH}_{2}$ PVA-AuNP were added for the last hour before assessment by flow cytometry, in order to determine if the materials reduce the fluorescence signal of the labeled antibodies. Our results showed that neither the NP nor the polymer significantly modified the fluorescence signal compared to LPS alone 

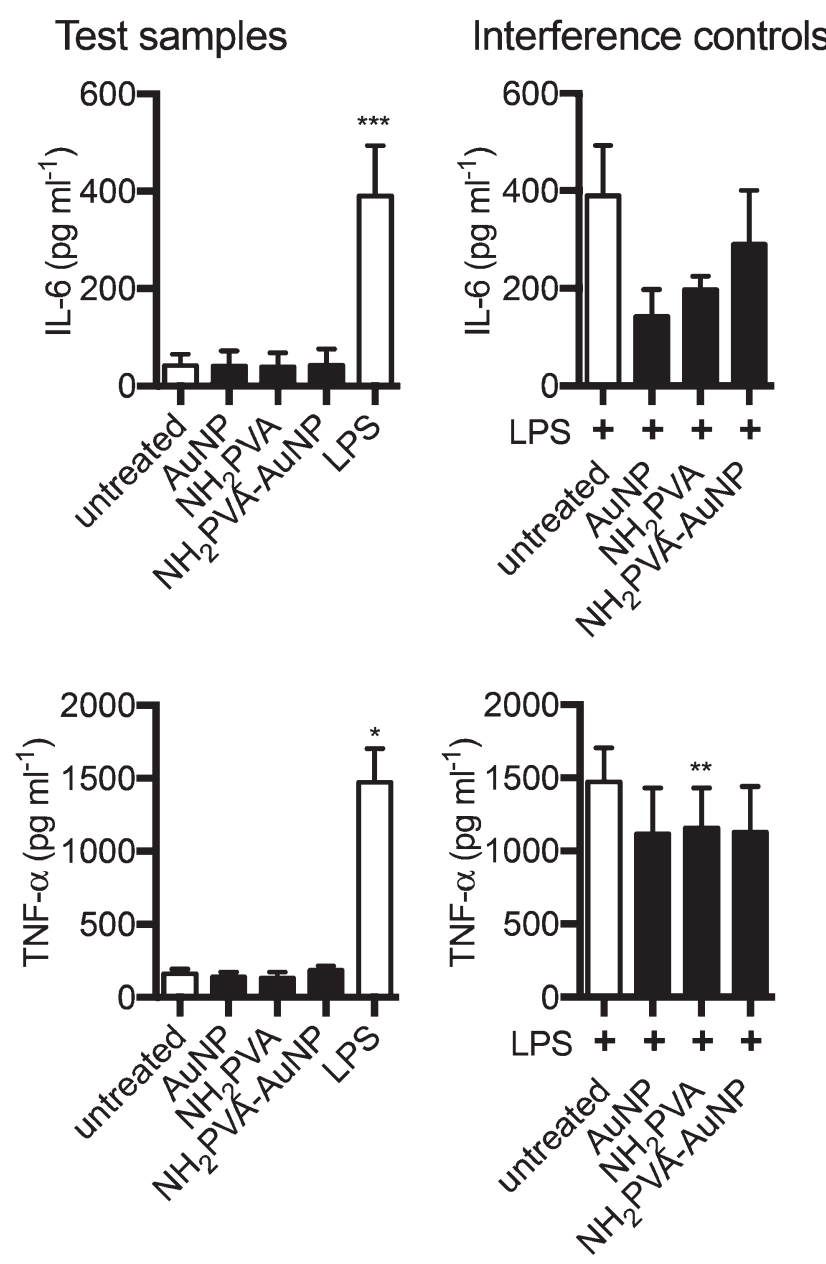

Fig. 5 Production of proinflammatory cytokines by macrophages after NP exposure. Test samples (left panels): J774.1 macrophages were incubated for $24 \mathrm{~h}$ at $37{ }^{\circ} \mathrm{C}$ with NP, the $\mathrm{NH}_{2} \mathrm{PVA}$ polymer or LPS. Interference controls (right panels): macrophages were incubated for $24 \mathrm{~h}$ at $37{ }^{\circ} \mathrm{C}$ with LPS $\left(100 \mathrm{ng} \mathrm{ml}^{-1}\right)$. NP or the $\mathrm{NH}_{2} \mathrm{PVA}$ polymer were added for the last hour of incubation. IL- 6 and TNF- $\alpha$ were quantified in culture supernatants by ELISA. Each bar represents mean \pm SEM of 5 independent experiments performed at least in duplicate. Asterisks $\left({ }^{*}, P<0.05 ;{ }^{* *}, P<0.01 ; * * *, P<0.001\right)$ indicate significant differences with the untreated group using one-way ANOVA followed by Dunnett's multiple comparison test.

(Fig. 6, middle panels). Because immune activation may increase cell autofluorescence and unspecific antibody binding, antibody isotype controls are necessary to confirm the specificity of the signal increase in LPS-treated macrophages. The median fluorescence intensity (MFI) for isotype control staining was not increased under any of the culture conditions, demonstrating that the signal measured for activation markers is specific (Fig. 6, right panels).

\section{Discussion}

Interest in NP use for biomedical applications is growing and there is an urgent need for reliable, rapid and universal methods to characterize NP interactions with immune cells. Herein we propose a rapid multi-parameter test to screen the NP impact on macrophages within one experimental day. We suggest flow cytometry as a standard method to investigate the proinflammatory potential of NP using a macrophage cell line, since it is an automated technique to quantify several parameters simultaneously, including cytotoxicity, NP uptake and proinflammatory-activating effects. The samples are measured on only one culture plate, thus allowing economical use of NP and reagents. We have shown exemplary results with polymercoated heterofunctionalized AuNP as a model, but this assay can be run with many different types of engineered nanomaterials, as shown in Fig. S4† with differently functionalized AuNP. In our laboratory we have also implemented this test for the screening of protein-based NP, poly-lactic- $c o$-glycolic acid (PLGA) NP, silica NP and micelles in order to select leading candidates between different synthesis strategies.

As a macrophage model, we used the widely investigated J774.1 murine cell line, which possesses characteristic functions of macrophages such as phagocytosis, antigen processing, cytokine production, and many of the surface markers. ${ }^{43}$ We found the data obtained with this cell line to be highly reproducible, allowing direct comparison of results even when tested on different days. MSC-2, a myeloid suppressor cell line, can also be used to run the screening assay (Fig. S4 $\dagger$ ), as can primary cells generated from animal or human samples. Indeed, the results obtained with this screening protocol for $\mathrm{NH}_{2}$ PVA-AuNP in J774.1 macrophages mirror data obtained previously for these NP in primary human immune cells. ${ }^{44}$ In any case, the first validation of NP using a cell line limits the number of experimental animals needed for further characterization and avoids the loss of human samples.

For a step-by-step overview of the interpretation of the data from the screening assay, we propose a flow chart that summarizes the key points of this process (Fig. 7). Because NPmacrophage interactions are dependent on particle properties ${ }^{45}$ the physico-chemical characterization of the panel of NP, including size, shape, charge, and colloidal stability also in the cell culture medium in which the cells are grown, is required before exposure. The working concentration for the screening protocol should be selected according to the planned biomedical application and based on the expected concentration in the organism. ${ }^{46,47}$ In addition, the working concentration should not lead to NP agglomeration. ${ }^{22}$ For $\mathrm{NH}_{2}$ PVA-AuNP, a potential application is the delivery of immunoactive drugs. We thus selected a working concentration $\left(10 \mu \mathrm{g} \mathrm{ml}^{-1}\right.$ of AuNP) that would be higher than the concentration needed to deliver an effective dose of the drug. At this dose, the NP demonstrated colloidal stability in media.

As a first step, the screening protocol rapidly assesses potential cytotoxicity. This step allows the selection of the candidates inducing the least cell death within a panel of NP. It also allows rapid screening of NP during the development process and may alert the necessity of design modifications if evident cytotoxicity is detected. As a second step, cellular uptake by macrophages is measured. In general, because 
Test samples

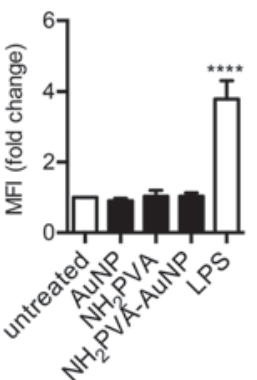

CD80

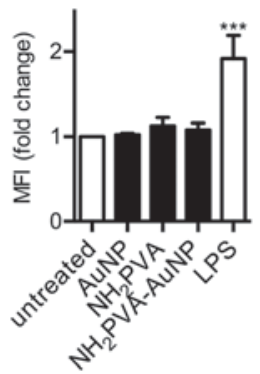

CD86
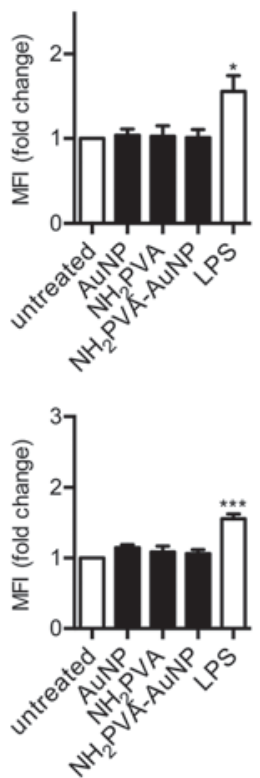

Interference controls

Isotype controls
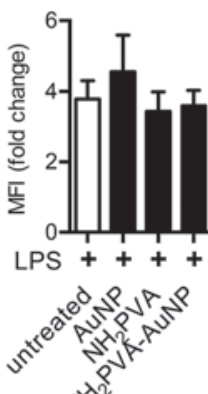

관

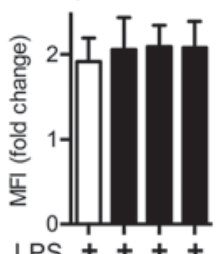

LPS ++++
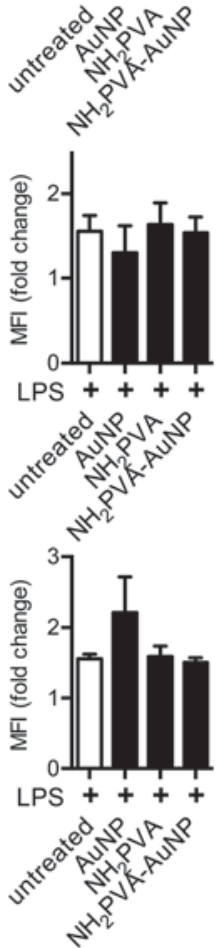
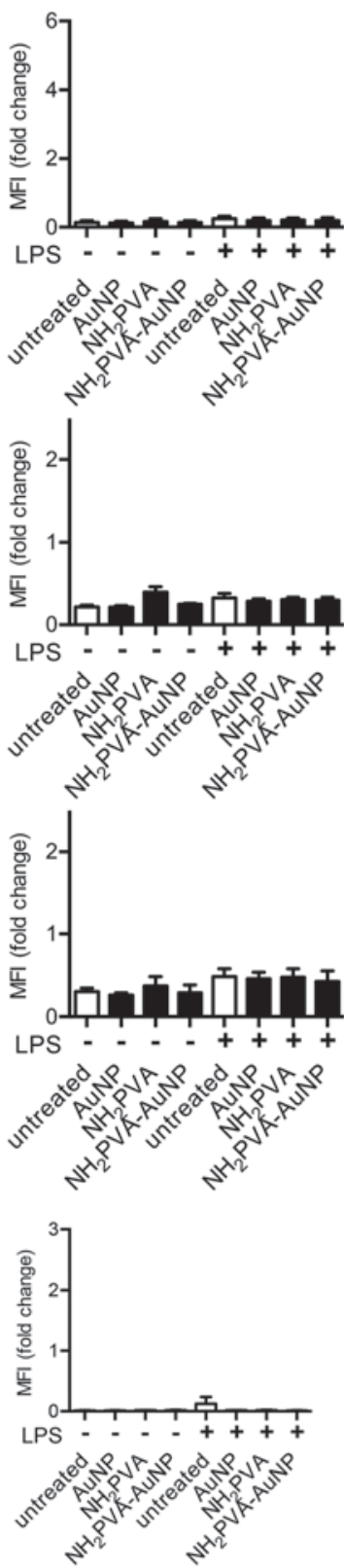

Fig. 6 Changes in surface activation markers on macrophages after NP exposure. Median fluorescence intensity (MFl; fold change compared to untreated sample) of activation markers on $\mathrm{J} 774.1$ macrophages after incubation is shown. Test samples, left panels: macrophages were incubated for $24 \mathrm{~h}$ at $37^{\circ} \mathrm{C}$ with NP, the $\mathrm{NH}_{2} \mathrm{PVA}$ polymer or LPS as shown in Fig. 5. Interference controls, middle panels: macrophages were incubated with LPS for $24 \mathrm{~h}$ as in Fig. 5. NP or the $\mathrm{NH}_{2}$ PVA polymer were added for the last hour of incubation. Isotype controls, right panels: median fluorescence intensity after staining of test samples and interference controls with unspecific isotype control antibodies is shown. Each bar represents mean \pm SEM of at least 3 independent experiments. Asterisks $(*, P<0.05 ; * * *, P<0.001 ; * * *, P<0.0001)$ indicate significant differences with the untreated group using one-way ANOVA followed by Dunnett's multiple comparison test.

macrophages lead to NP clearance, a low uptake is desirable and the NP candidates should be selected accordingly. Low capture by macrophages will result in low NP clearance, allowing them more time to reach their target cells in the body. ${ }^{43}$ One widely used coating for NP which considerably reduces their uptake by macrophages is polyethylene glycol (PEG). ${ }^{48}$ In the previously established AuNP library in our laboratory, ${ }^{24}$ the coating strategies strongly modify the uptake of $17 \mathrm{~nm}$ gold core NP by macrophages. ${ }^{19}$ For instance PEG-coated AuNP showed a lower uptake than PVA-coated NP, and carboxyl-functionalization resulted in a lower uptake than amino-functionalization. For specific applications with the aim to stimulate or to inhibit 


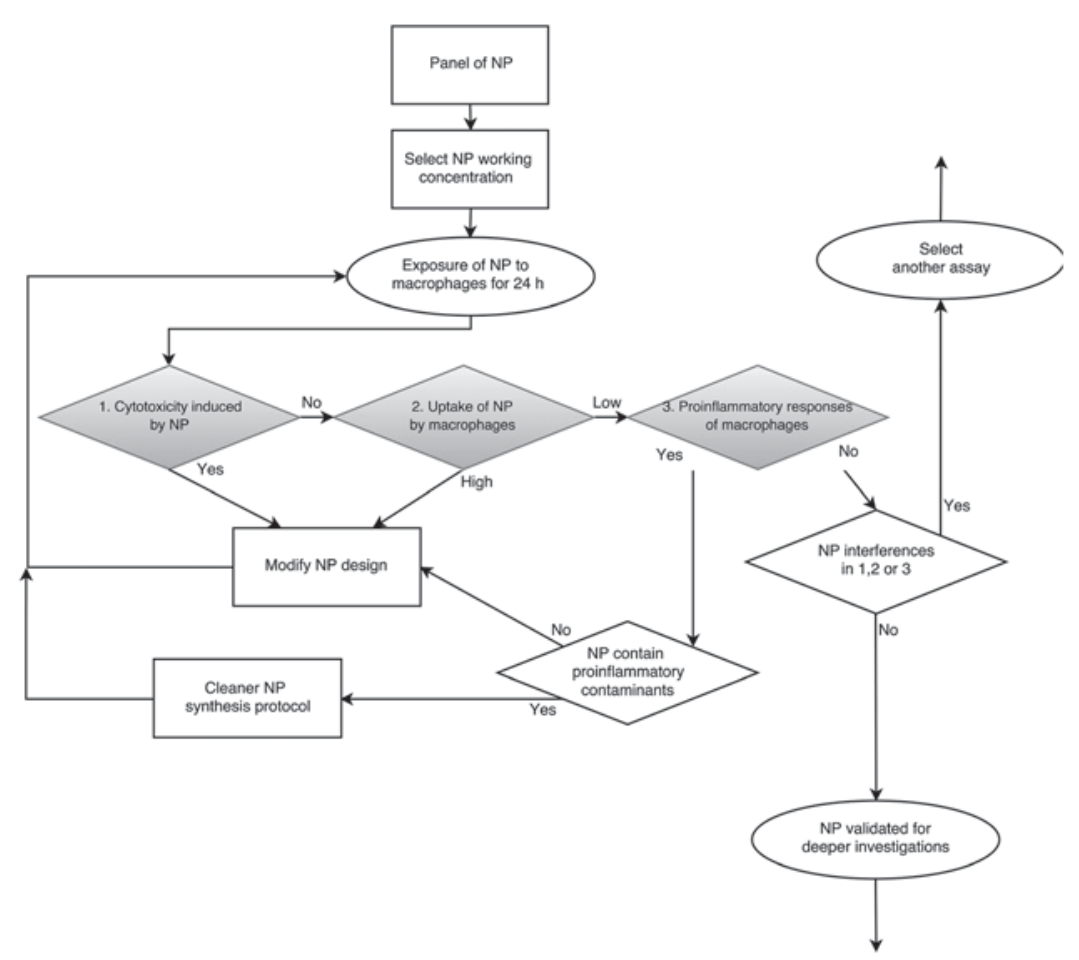

Fig. 7 Flow chart guide to data interpretation. Flow chart describing the different steps that a panel of NP must pass through in order to be validated for deeper investigations.

an immune response, macrophages may be themselves the target of the NP, in which case the selection of NP with high cellular uptake may be appropriate. ${ }^{49,50}$

As third step of the screening assay, the NP immune effects are determined by two parameters: the concentration of cytokines in the culture supernatant and the expression of typical markers on the surface of activated macrophages. Cytokines will diffuse rapidly in the body to initiate a generalized immune response, whereas surface markers are important for local cell-to-cell interactions. Except in specific applications where immune activation is desired, such as in vaccination strategies, the NP that do not induce immunostimulation should be selected in order to avoid unwanted proinflammatory effects in the organism. ${ }^{49}$ Any detected immunostimulating effect may be caused by the NP themselves, in which case the design of the particle may need to be adjusted. On the other hand, the observed immunoactivation may originate from immuno-contaminants introduced during synthesis. This may be verified using a further test, the limulus amebocyte lysate (LAL) assay, ${ }^{51,52}$ which is used as a gold standard to test for endotoxin contaminants. If contaminations are detected, the conventional depyrogenation processes are often not suitable for $\mathrm{NP}^{53}$ so that the NP synthesis process may need to be revisited.

Finally, because NP are well known to interfere with different aspects of biological assays ${ }^{33,34}$ and because this may lead to incorrect interpretation of the NP impact on macrophages, the screening protocol includes essential interference controls at all steps. If interferences are detected during one of the steps of the test, a complementary assay relying on a different detection method should be considered. In this report, we noted that both the AuNP and the polymer decrease the ELISA absorbance reading at $450 \mathrm{~nm}$ in the interference control for IL-6 and TNF- $\alpha$ (Fig. 5). However, other types of NP will not necessarily cause these interferences. We found it unlikely that the gold core directly interferes with the absorbance reading or the enzyme activity, ${ }^{26}$ because the polymer alone also reduced the signal. The lower signal intensity is thus probably due to cytokine adsorption to the material surface. To verify IL- 6 and TNF- $\alpha$ production by alternative methods, intracellular cytokines could be assessed with flow cytometry, or cytokine mRNA levels could be measured by quantitative polymerase chain reaction (qPCR)..$^{54}$

The one-plate screening assay presented here is designed to give a rapid overview of the different aspects of NP-macrophage interactions. For a more detailed investigation of specific findings, we present a list of possible assays (Table 1). For instance, several methods are available to further characterize the mechanisms of toxicity (reviewed in ref. 15, 22, 47 and 55). For the assessment of NP uptake, the flow cytometry technique used in the screening protocol requires fluorescent labeling of the NP. In general, it cannot be excluded that the dye may affect NP uptake, ${ }^{24}$ or that the fluorophore could detach from the core, or that fluorescence may be quenched by the NP, as has been shown for AuNP. ${ }^{56}$ After the initial screening, we therefore suggest to confirm the uptake for selected NP candidates by using a second method adapted to the type of NP used (for instance, inductively coupled optical emission spectrometry 
Table 1 Examples of further investigation procedures

\begin{tabular}{|c|c|c|c|}
\hline & Question & Method & Ref. \\
\hline \multirow[t]{17}{*}{ Toxicity } & \multirow[t]{4}{*}{ Are the cells alive? (metabolic activity) } & Calcein acetoxymethyl (CAM) (lysosomal activity) & \\
\hline & & Neutral red uptake (NRU) & 59 \\
\hline & & Tetrazolium salt (MTT, MTS, XTT, WST) assay & 60 \\
\hline & & AlarmBlue $=$ Resazurin assay & 61 \\
\hline & \multirow[t]{2}{*}{ Do NP disrupt membrane integrity? } & Trypan blue assay & 62 \\
\hline & & Lactate dehydrogenase (LDH) release assay & 63 and 34 \\
\hline & \multirow[t]{2}{*}{ Do NP induce mitochondrial damage? } & DiLC iodide (mitochondrial membrane potential) & 64 \\
\hline & & qPCR of mitochondrial DNA & 65 \\
\hline & \multirow[t]{2}{*}{ Do the NP induce genotoxicity? } & Comet assay $=$ single cell gel electrophoresis (SCGE) assay (DNA breaks) & 66 \\
\hline & & Micronucleus (MN) assay (chromosomal breaks) & $66-68$ \\
\hline & \multirow[t]{5}{*}{ Do NP induce ROS? } & Nitric oxide (NO) assay & \multirow[t]{5}{*}{69} \\
\hline & & Peroxidase assay & \\
\hline & & Electron spin resonance assay & \\
\hline & & Levels of glutathione & \\
\hline & & Dichlorodihydrofluorescein diacetate (DCFH-DA) assay & \\
\hline & Do NP induce red blood cell lysis? & Hemolytic assay & 70 \\
\hline & Do NP cause clotting? & Platelet aggregation assay & 71 \\
\hline \multirow[t]{2}{*}{ Uptake } & Where do NP accumulate inside cells? & $\begin{array}{l}\text { Confocal microscopy with co-staining for specific organelles } \\
\text { (e.g. Lysotracker) }\end{array}$ & 57 \\
\hline & By which pathway are the NP taken up? & $\begin{array}{l}\text { Pharmacological inhibitors and gene-deficient cell lines to pinpoint } \\
\text { specific uptake pathways }\end{array}$ & 58 and 72 \\
\hline \multirow{5}{*}{$\begin{array}{l}\text { Immune- } \\
\text { activation }\end{array}$} & Which cytokines are produced? & Intracellular staining and RT-qPCR & 54 \\
\hline & \multirow{2}{*}{ Is the sample contaminated with LPS? } & Limulus amebocyte lysate (LAL) assay & 73 \\
\hline & & HEK-Blue $\mathrm{TM}^{\mathrm{TM}} \mathrm{TLR}$ reporter cells & 52 \\
\hline & Do NP activate complement? & ELISA of complement cascade intermediates & 74 \\
\hline & Do NP influence antigen presentation? & $\begin{array}{l}\text { DQ ovalbumin to determine antigen uptake and processing } \\
\text { Antibodies to detect MHC-peptide complex on the cell surface }\end{array}$ & 75 \\
\hline All & $\begin{array}{l}\text { Can the observations be extended to } \\
\text { other cell types and primary cells? }\end{array}$ & $\begin{array}{l}\text { Repeat key tests with mouse bone marrow-derived macrophages or } \\
\text { dendritic cells, primary isolated immune cells of interest, human } \\
\text { cells such as monocyte-derived dendritic cells, endothelial cells }\end{array}$ & 76 and 77 \\
\hline
\end{tabular}

Table listing tests that may be considered in order to further investigate NP interactions with cells. References refer to representative examples where the different assays have been used.

(ICP-OES) may be used to quantify gold uptake ${ }^{24}$ ). To determine in which cell compartment the NP accumulate, a standard technique is to use confocal microscopy and cells labeled with dyes that allow visualization of organelles, such as the endosomes and lysosomes. ${ }^{57}$ To determine which is the main mechanism of uptake, ${ }^{11}$ pharmaceutical and genetic inhibitors of phagocytosis can be employed. ${ }^{58}$

In conclusion, we present a one-plate automated screening protocol for the rapid selection of potential NP candidates for biomedical applications, based on their impact on J774.1 macrophages. The protocol presented herein can furthermore be easily adapted to screen the impact of NP on other cells of interest such as endothelial cell lines, human cell lines or even primary cells, allowing for additional versatility.

\section{Conflict of interest}

The authors declare no financial conflicts of interest.

\section{Acknowledgements}

This study was supported by the National Center of Competence in Research (NCCR) for Bio-Inspired Materials and the Swiss National Science Foundation grants 310030_156871 and 310030_156372. The authors thank Dr Sandor Balog for the Mathematica script to analyze DDLS data, Jérôme Widmer for technical assistance and Leatitia Häni for her help in preparing and functionalizing the used particles.

\section{References}

1 A. Anselmo and S. Mitragotri, Bioeng. Transl. Med., 2016, 1, 10-29.

2 M. Auffan, J. Rose, J.-Y. Y. Bottero, G. V. Lowry, J.-P. P. Jolivet and M. R. Wiesner, Nat. Nanotechnol., 2009, 4, 634-641.

3 S. K. Nune, P. Gunda, P. K. Thallapally, Y.-Y. Y. Lin, M. L. Forrest and C. J. Berkland, Expert Opin. Drug Delivery, 2009, 6, 1175-1194.

4 T. Sun, Y. S. Zhang, B. Pang, D. C. Hyun, M. Yang and Y. Xia, Angew. Chem., Int. Ed., 2014, 53, 12320-12364.

5 E. Blanco, H. Shen and M. Ferrari, Nat. Biotechnol., 2015, 33, 941-951.

6 W. H. De Jong and P. J. Borm, Int. J. Nanomed., 2008, 3, 133-149.

7 S. Wilhelm, A. Tavares, Q. Dai, S. Ohta, J. Audet, H. Dvorak and W. Chan, Nat. Rev. Mater., 2016, 1, 16014. 
8 J. Xie, S. Lee and X. Chen, Adv. Drug Delivery Rev., 2010, 62, 1064-1079.

9 I. Lynch, A. Ahluwalia, D. Boraschi, H. Byrne, B. Fadeel, P. Gehr, A. Gutleb, M. Kendall and M. Papadopoulos, Bionanomaterials, 2013, 14, 195-216.

10 P. Murray and T. Wynn, Nat. Rev. Immunol., 2011, 11, 723-737.

11 A. Aderem and D. Underhill, Annu. Rev. Immunol., 1999, 17, 593-623.

12 R. Weissleder, M. Nahrendorf and M. Pittet, Nat. Mater., 2014, 13, 125-138.

13 M. Longmire, P. L. Choyke and H. Kobayashi, Nanomedicine, 2008, 3, 703-717.

14 T. Wynn, A. Chawla and J. Pollard, Nature, 2013, 496, 445-455.

15 L. Yildirimer, N. T. Thanh, M. Loizidou and A. M. Seifalian, Nano Today, 2011, 6, 585-607.

16 T. Kusaka, M. Nakayama, K. Nakamura, M. Ishimiya, E. Furusawa and K. Ogasawara, PLoS One, 2014, 9, e92634.

17 H. Chang, J. Y. Yhee, G. H. Jang, D. G. You, J. H. Ryu, Y. Choi, J. H. Na, J. H. Park, K. H. Lee, K. Choi, K. Kim and I. C. Kwon, J. Controlled Release, 2016, 244, 205-213.

18 W.-K. Oh, S. Kim, M. Choi, C. Kim, Y. Jeong, B.-R. Cho, J.-S. Hahn and J. Jang, ACS Nano, 2010, 4, 5301-5313.

19 C. Kelly, C. Lawlor, C. Burke, J. Barlow, J. Ramsey, C. Jefferies and S.-A. Cryan, J. Liposome Res., 2014, 25, 211-221.

20 D. Vanhecke, L. Rodriguez-Lorenzo, M. J. Clift, F. Blank, A. Petri-Fink and B. Rothen-Rutishauser, Nanomedicine, 2014, 9, 1885-1900.

21 F. Sambale, F. Stahl, F. Rüdinger, D. Seliktar, C. Kasper, D. Bahnemann and T. Scheper, J. Nanomater., 2015, 2015, 1-16.

22 A. Dhawan and V. Sharma, Anal. Bioanal. Chem., 2010, 398, 589-605.

23 R. Guadagnini, B. Halamoda Kenzaoui, L. Walker, G. Pojana, Z. Magdolenova, D. Bilanicova, M. Saunders, L. Juillerat-Jeanneret, A. Marcomini, A. Huk, M. Dusinska, L. M. Fjellsbø, F. Marano and S. Boland, Nanotoxicology, 2015, 9(Suppl 1), 13-24.

24 L. Rodriguez-Lorenzo, K. Fytianos, F. Blank, C. von Garnier, B. Rothen-Rutishauser and A. Petri-Fink, Small, 2014, 10, 1341-1350.

25 T. Moore, L. Rodriguez-Lorenzo, V. Hirsch, S. Balog, D. Urban, C. Jud, B. Rothen-Rutishauser, M. Lattuada and A. Petri-Fink, Chem. Soc. Rev., 2015, 44, 6287-6305.

26 E. Boisselier and D. Astruc, Chem. Soc. Rev., 2009, 38, 17591782.

27 S. Balog, L. Rodriguez-Lorenzo, C. A. Monnier, M. ObiolsRabasa, B. Rothen-Rutishauser, P. Schurtenberger and A. Petri-Fink, Nanoscale, 2015, 7, 5991-5997.

28 J. Gebauer, M. Malissek, S. Simon, S. Knauer, M. Maskos, R. Stauber, W. Peukert and L. Treuel, Langmuir, 2012, 28, 9673-9679.

29 R. Murdock, L. Braydich-Stolle, A. Schrand, J. Schlager and S. Hussain, Toxicol. Sci., 2008, 101, 239-253.
30 G. Kleveta, K. Borzęcka, M. Zdioruk, M. Czerkies, H. Kuberczyk, N. Sybirna, A. Sobota and K. Kwiatkowska, J. Cell. Biochem., 2012, 113, 80-92.

31 S. Elmore, Toxicol. Pathol., 2007, 35, 495-516.

32 J. M. Wörle-Knirsch, K. Pulskamp and H. F. Krug, Nano Lett., 2006, 6, 1261-1268.

33 A. Kroll, M. H. Pillukat, D. Hahn and J. Schnekenburger, Arch. Toxicol., 2012, 86, 1123-1136.

34 A. Kroll, M. Pillukat, D. Hahn and J. Schnekenburger, Eur. J. Pharm. Biopharm., 2009, 72, 370-377.

35 H. Gustafson, D. Holt-Casper, D. Grainger and H. Ghandehari, Nano Today, 2015, 10, 487-510.

36 R. M. Zucker, E. J. Massaro, K. M. Sanders, L. L. Degn and W. K. Boyes, Cytometry, Part A, 2010, 77A, 677-685.

37 R. Friedrich, C. Janko, M. Liebl, L. Trahms, M. Stapf, I. Hilger, S. Lyer, C. Alexiou, M. Poettler, P. Tripal, J. Zaloga, I. Cicha, S. Dürr, J. Nowak, S. Odenbach and I. Slabu, Int. J. Nanomed., 2015, 10, 4185-4201.

38 H. Suzuki, T. Toyooka and Y. Ibuki, Environ. Sci. Technol., 2007, 41, 3018-3024.

39 L. Jiang, R. Tixeira, S. Caruso, G. Atkin-Smith, A. Baxter, S. Paone, M. Hulett and I. Poon, Nat. Protoc., 2016, 11, 655-663.

40 S. Opal, J. Endotoxin Res., 2002, 8, 473-476.

41 Z. Chang, M. Novotney and T. Suzuki, Cell Res., 1992, 2, 5366.

42 D. Mosser and J. Edwards, Nat. Rev. Immunol., 2008, 8, 958-969.

43 P. RAL and I. NAKOINZ, Nature, 1975, 257, 393-394.

44 K. Fytianos, L. Rodriguez-Lorenzo, M. J. Clift, F. Blank, D. Vanhecke, C. von Garnier, A. Petri-Fink and B. RothenRutishauser, Nanomedicine, 2015, 11, 633-644.

45 P. Rivera-Gil, D. Aberasturi, V. Wulf, B. Pelaz, P. Pino, Y. Zhao, J. Fuente, I. Larramendi, T. Rojo, X.-J. Liang and W. Parak, Acc. Chem. Res., 2013, 46, 743-749.

46 H. Krug and P. Wick, Angew. Chem., Int. Ed., 2011, 50, 1260-1278.

47 B. Kong, J. H. Seog, L. M. Graham and S. B. Lee, Nanomedicine, 2011, 6, 929-941.

48 J. Jokerst, T. Lobovkina, R. Zare and S. Gambhir, Nanomedicine, 2011, 6, 715-728.

49 D. Smith, J. Simon and J. Baker, Nat. Rev. Immunol., 2013, 13, 592-605.

50 D. Getts, L. Shea, S. Miller and N. King, Trends Immunol., 2015, 36, 419-427.

51 Y. Li and D. Boraschi, Nanomedicine, 2016, 11, 269-287.

52 S. Smulders, J.-P. Kaiser, S. Zuin, K. Landuyt, L. Golanski, J. Vanoirbeek, P. Wick and P. Hoet, Part. Fibre Toxicol., 2012, 9, 1-11.

53 M. A. Dobrovolskaia and S. E. McNeil, J. Controlled Release, 2013, 172, 456-466.

54 K. Sullivan, J. Cutilli, L. Piliero, D. Ghavimi-Alagha, S. Starr, D. Campbell and S. Douglas, Clin. Diagn. Lab. Immunol., 2000, 7, 920-924.

55 S. Arora, J. Rajwade and K. Paknikar, Toxicol. Appl. Pharmacol., 2011, 258. 
56 E. Dulkeith, A. C. Morteani, T. Niedereichholz, T. A. Klar, J. Feldmann, S. A. Levi, F. C. van Veggel, D. N. Reinhoudt, M. Möller and D. I. Gittins, Phys. Rev. Lett., 2002, 89, 203002.

57 B. Rothen-Rutishauser, D. A. Kuhn, Z. Ali, M. Gasser, F. Amin, W. J. Parak, D. Vanhecke, A. Fink, P. Gehr and C. Brandenberger, Nanomedicine, 2014, 9, 607-621.

58 D. Dutta and J. Donaldson, Cell. Logist., 2012, 2, 203-208.

59 G. Repetto, A. del Peso and J. Zurita, Nat. Protoc., 2008, 3, 1125-1131.

60 M. Rösslein, J. Elliott, M. Salit, E. Petersen, C. Hirsch, H. Krug and P. Wick, Chem. Res. Toxicol., 2015, 28, 21-30.

61 D. Breznan, D. Das, C. MacKinnon-Roy, B. Simard, P. Kumarathasan and R. Vincent, Toxicol. in Vitro, 2015, 29, 142-147.

62 W. Strober, Current Protocols in Immunology, wiley, 2015, vol. 111.

63 X. Han, R. Gelein, N. Corson, P. Wade-Mercer, J. Jiang, P. Biswas, J. Finkelstein, A. Elder and G. Oberdörster, Toxicology, 2011, 287, 99-104.

64 H. Rottenberg and S. Wu, Biochim. Biophys. Acta, Mol. Cell Res., 1998, 1404, 393-404.

65 S. Hunter, D. Jung, R. Giulio and J. Meyer, Methods, 2010, 51, 444-451.

66 L. Bowman, V. Castranova and M. Ding, Single Cell Gel Electrophoresis Assay (Comet Assay) for Evaluating
Nanoparticles-Induced DNA Damage in Cells, springer, 2012, vol. 906.

67 H. Karlsson, Anal. Bioanal. Chem., 2010, 398, 651-666.

68 Z. Magdolenova, Y. Lorenzo, A. Collins and M. Dusinska, J. Toxicol. Environ. Health, Part A, 2012, 75, 800-806.

69 M. Roesslein, C. Hirsch, J.-P. Kaiser, H. Krug and P. Wick, Int. J. Mol. Sci., 2013, 14, 24320-24337.

70 M. Dobrovolskaia, J. Clogston, B. Neun, J. Hall, A. Patri and S. McNeil, Nano Lett., 2008, 8, 2180-2187.

71 V. Miller, L. Hunter, K. Chu, V. Kaul, P. Squillace, J. Lieske and M. Jayachandran, Nanomedicine, 2009, 4, 725-733.

72 A. Ivanov, Pharmacological Inhibition of Endocytic Pathways: Is It Specific Enough to Be Useful?, springer, 2008, vol. 440.

73 B. Neun and M. Dobrovolskaia, Detection and Quantitative Evaluation of Endotoxin Contamination in Nanoparticle Formulations by LAL-Based Assays, 2011, vol. 697.

74 T. Mollnes, S. Jokiranta, L. Truedsson, B. Nilsson, S. de Cordoba and M. Kirschfink, Mol. Immunol., 2007, 44, 38383849.

75 A. Mant, F. Chinnery, T. Elliott and A. Williams, Immunology, 2012, 136, 163-175.

76 O. Gamucci, A. Bertero, M. Malvindi, S. Sabella, P. Pompa, B. Mazzolai and G. Bardi, J. Vis. Exp., 2014.

77 N. Monteiro-Riviere and J. Riviere, Nanotoxicology, 2009, 3, 188-193. 